\title{
Analyzing catchment behavior through catchment modeling in the Gilgel Abay, Upper Blue Nile River Basin, Ethiopia
}

\author{
S. Uhlenbrook ${ }^{1,2}$, Y. Mohamed ${ }^{1,2,3}$, and A. S. Gragne ${ }^{4}$ \\ ${ }^{1}$ UNESCO-IHE, Department of Water Engineering, P.O. Box 3015, 2601 DA Delft, The Netherlands \\ ${ }^{2}$ Delft University of Technology, Department of Water Resources, P.O. Box 5048, 2600 GA Delft, The Netherlands \\ ${ }^{3}$ Hydraulic Research Station, P.O. Box 318, Wad Medani, Sudan \\ ${ }^{4}$ Jimma University, Department of Water Resources and Environmental Engineering, Jimma, Ethiopia
}

Received: 15 February 2008 - Published in Hydrol. Earth Syst. Sci. Discuss.: 20 March 2008

Revised: 13 August 2010 - Accepted: 11 September 2010 - Published: 29 October 2010

\begin{abstract}
Understanding catchment hydrological processes is essential for water resources management, in particular in data scarce regions. The Gilgel Abay catchment (a major tributary into Lake Tana, source of the Blue Nile) is undergoing intensive plans for water management, which is part of larger development plans in the Blue Nile basin in Ethiopia. To obtain a better understanding of the water balance dynamics and runoff generation mechanisms and to evaluate model transferability, catchment modeling has been conducted using the conceptual hydrological model HBV. Accordingly, the catchment of the Gilgel Abay has been divided into two gauged sub-catchments (Upper Gilgel Abay and Koga) and the un-gauged part of the catchment. All available data sets were tested for stationarity, consistency and homogeneity and the data limitations (quality and quantity) are discussed.

Manual calibration of the daily models for three different catchment representations, i.e. (i) lumped, (ii) lumped with multiple vegetation zones, and (iii) semi-distributed with multiple vegetation and elevation zones, showed good to satisfactory model performances with Nash-Sutcliffe efficiencies $R_{\text {eff }}>0.75$ and $>0.6$ for the Upper Gilgel Abay and Koga sub-catchments, respectively. Better model results could not be obtained with manual calibration, very likely due to the limited data quality and model insufficiencies. Increasing the computation time step to 15 and 30 days improved the model performance in both sub-catchments to $R_{\text {eff }}>0.8$. Model parameter transferability tests have been conducted by interchanging parameters sets between the two gauged sub-catchments. Results showed poor performances for the daily models $\left(0.30<R_{\text {eff }}<0.67\right)$, but better
\end{abstract}

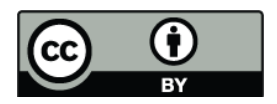

Correspondence to: S. Uhlenbrook (s.uhlenbrook@unesco-ihe.org) performances for the 15 and 30 days models, $R_{\text {eff }}>0.80$. The transferability tests together with a sensitivity analysis using Monte Carlo simulations (more than 1 million model runs per catchment representation) explained the different hydrologic responses of the two sub-catchments, which seems to be mainly caused by the presence of dambos in Koga sub-catchment. It is concluded that daily model transferability is not feasible, while it can produce acceptable results for the 15 and 30 days models. This is very useful for water resources planning and management, but not sufficient to capture detailed hydrological processes in an ungauged area.

\section{Introduction}

The Nile Basin is shared by ten riparian countries and is the life source for more than 160 million people living in the basin. The Blue Nile, originating from the Ethiopian Plateau, is the major source of the Nile water, contributing to more than $60 \%$ of the Nile total flow at Aswan in Egypt (Conway and Hulme, 1993; Sutcliffe and Parks, 1999). Irrigation, hydropower, rain fed systems and flood management are the key water resource development needs in Ethiopia and in the Nile region in general. Therefore, understanding the water balance and its spatial and temporal dynamics in the headwaters is of high importance.

A number of studies have been conducted on the Nile River; however, due to absence of data and other priorities very few cover the hydrology of the Blue Nile and the Upper Blue Nile in particular. Until recently, the old USBR study from 1964 on development options in the Upper Blue Nile is the most cited reference in the literature.

Published by Copernicus Publications on behalf of the European Geosciences Union. 
However, recently more research has been conducted, e.g., JICA (1997), BCEOM (1999), Conway and Hume (1993), Mishra et al. (2003), Kebede et al. (2005), Steenhuis et al. (2008), among others.

About $60 \%$ of the Lake Tana catchment (source of the Blue Nile) is not gauged. This contributes to the uncertainty of the runoff yield estimates into the lake (MoWR, 2005) and subsequently to the future generated downstream flows. Some researchers computed the total inflow to Lake Tana backward from lake outflows (MoWR, 2005). The water balance studies of Lake Tana indicated that more than $93 \%$ of the inflow to the lake originates from four main tributary rivers: Gilgel Abay, Gumera, Rib and Megech (Tarekegn and Tadege, 2005; Kebede et al., 2006). The Gilgel-Abay alone contributes about $60 \%$ of the inflow to the lake (Tessema, 2006). Generally, little is known about the hydrology of the Gilgel Abay catchment, which is one of the main tributaries of Lake Tana.

For operational water resources management, hydrological models are essential for understanding and predicting the spatial and temporal variability in water resources systems (e.g., Lidén and Harlin, 2000; Uhlenbrook et al., 2004). In this regard, predicting impacts of land use or climate change on hydrology, e.g., on runoff or recharge is an important challenge for hydrology (e.g. Sivapalan et al., 2003; Uhlenbrook 2009). Thus, catchment scale studies of the Gilgel-Abay help to identify the water balance dynamics and the runoff generation processes, and hence provide further insights on lake level fluctuations to assess the influence on Blue Nile flow. Therefore, the main objective of this paper is to obtain a deeper understanding of the dominant hydrological processes of the Gilgel Abay using rainfall-runoff modeling, assessing model complexity, and to provide an overview of model transferability at different time-scales.

\section{The study area}

The Gilgel Abay catchment $\left(5000 \mathrm{~km}^{2}\right)$ is the largest of the main four sub-catchments of Lake Tana, and provides about $60 \%$ of the lake inflow. The catchment includes the two gauged sub-catchments, namely the Upper Gilgel Abay $\left(1654 \mathrm{~km}^{2}\right)$ and Koga $\left(307 \mathrm{~km}^{2}\right)$, see Figs. 1 and 2. With elevation ranging from $1800 \mathrm{~m}$ to $3500 \mathrm{~m}$ a.m.s.l., the topography is rugged in the southern part of the catchment and the periphery in the west and southeast, while the remaining part is a typical plateau with gentle slopes. The geology is composed of quaternary basalts and alluviums. The soils are dominated by clays and clayey loams. The dominant land use units are agricultural $65 \%$ and agro-pastoral land $33 \%$ (BECOM, 1999). Among these the rainfed agriculture is prevailing covering $74 \%$ and $64 \%$ of Upper Gilgel Abay and Koga sub-catchments, respectively. In general, there are no strong links between elevation and land use in the basin, however, seasonal wetlands (dambos or marshland)

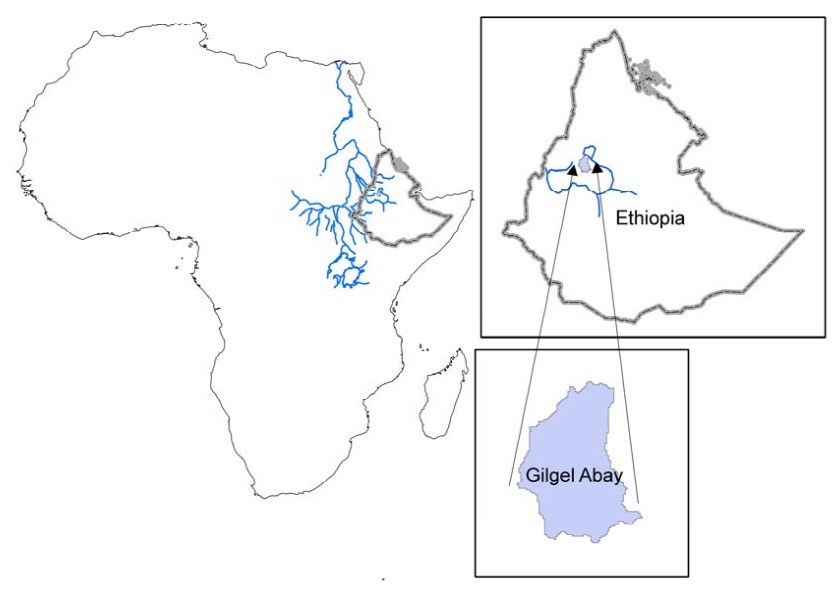

Fig. 1. Location of Gilgel Abay catchment, Blue Nile, Ethiopia.

are observed mostly in the gentle slopes of the catchment, as shown in Fig. 2. As discussed by von der Heyden and New (2003), the influence of dambos in enhancing catchment evapotranspiration and base flow while reducing or retarding floods is still not well understood.

The rainfall over Gilgel Abay and Upper Blue Nile in general, originates from moist air coming from the Atlantic and Indian oceans following the north-south movement of the Inter Tropical Convergence Zone (Mohamed et al., 2005). The study area has one main rainy season between June and September, receiving about 70 to $90 \%$ of the annual rainfall (Kebede et al., 2006; Tarekegn and Tadege, 2005). The rainfall data from meteorological stations indicate significant spatial variability of rainfall following the topography, with a decreasing trend from south to north. The temperature variations are small throughout the year (BCEOM, 1999). There are two discharge gauging stations, equipped with staff gauges and water level readings have been taken twice a day (Fig. 2).

\section{Materials and methods}

\subsection{Validation of input data}

The main input data to the HBV model are: daily rainfall, daily temperature, and monthly potential evapotranspiration, beside mean daily temperatures to interpolate daily potential evapotranspiration. In general, the data to be used for hydrological simulations should be tested first for stationary, consistent and homogeneous (Dahmen and Hall, 1990). We have done intensive and rigorous analyses of the hydro-meteorological data, including: visual screening of the data and plausibility checks, data consistency tests (daily, monthly, annual), trend analysis, and split-record test for the stationarity of the mean and variance. To save, space, only key findings of the data validation results are reported here. 


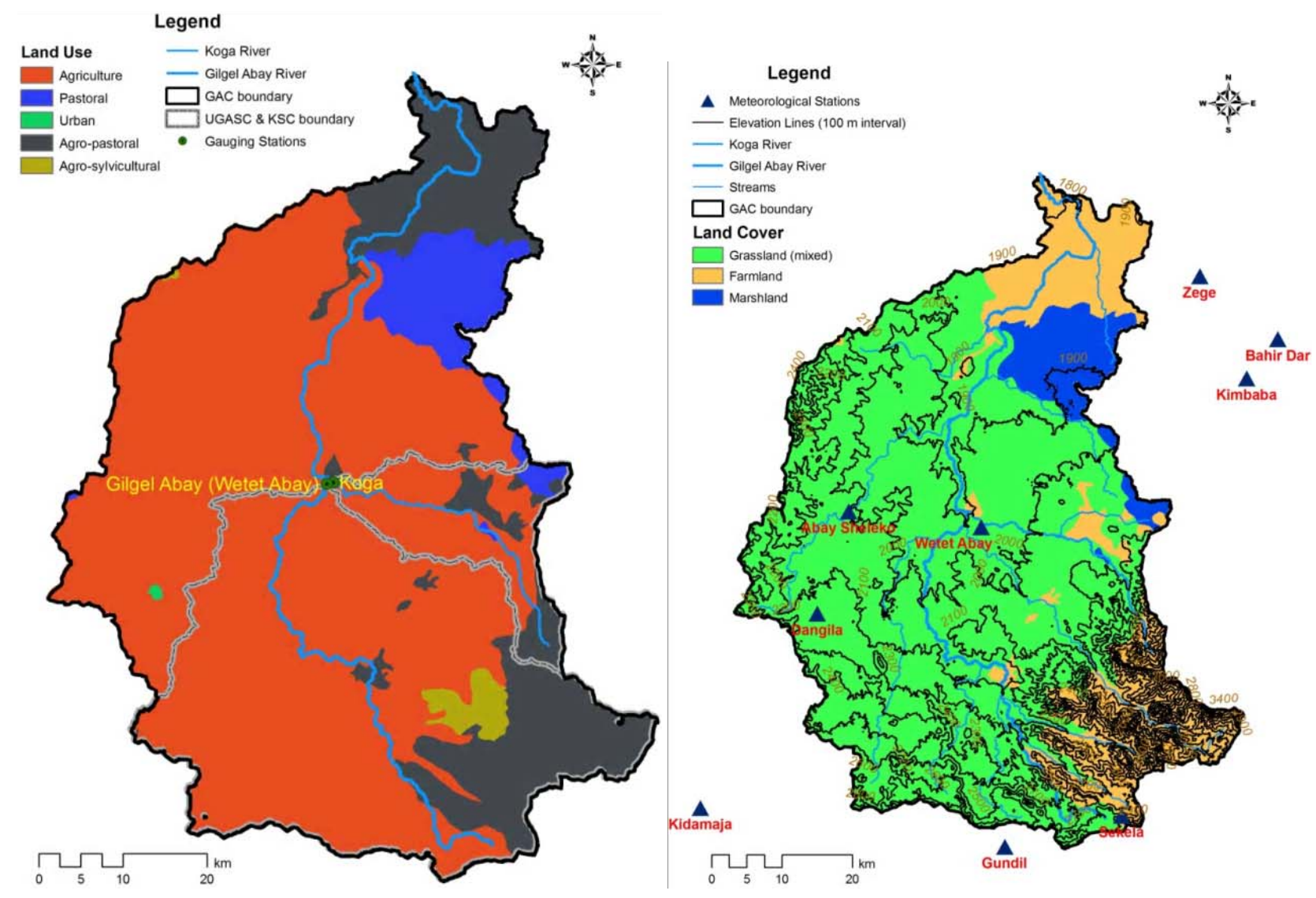

Fig. 2. Gilgel Abay catchment: sub-catchment boundaries, land use, gauging network, contour lines, river network and vegetation cover.

The records of nine rain gauges shown in Fig. 2 have been processed. Data gaps have been filled using regression and spatial interpolation methods. The discharge data were obtained from the Ministry of Water Resources Ethiopia, which were based on water level measurements (daily at 06:00 a.m. and 06:00 p.m.) using an occasionally updated rating curve of the stations. The daily discharge time series were checked for outliers and trends. The 15 (half monthly) and 30 days (monthly) data sets were aggregated from daily measurements. Field visits to the study site have been conducted to inspect the gauging stations and to get a better understanding of the prevailing land cover and land use in the area and its relation to the hydrological processes.

Areal time series (model inputs) of daily rainfall, temperature and runoff (for model calibration and validation) have been derived from point measurements using the Thiessen polygon method. In view of the limited number of stations, the Thiessen method is considered suitable to represent areal characteristics of rainfall over the Upper Gilgel Abay and Koga sub-catchments. The four rainfall stations Dangila, Gundil, Sekela and Wetet Abay were used to compute areal rainfall over the Upper Gilgel Abay, while the three stations Wetet Abay, Dangila and Gundil were used for the Koga sub-catchment; see location in Fig. 2. Similarly, areal temperature for the Upper Gilgel Abay was derived from three stations (Wetet Abay, Dangila and Gundil), while for the Koga sub-catchment the station Wetet Abay was assumed to represent the areal temperature.

To account for rainfall and temperature variability with elevation in the distributed HBV model, simple regression relations of rainfall vs. elevation, and temperature vs. elevation have been derived from point station data. From the long term mean values of the 6 gauging stations, it is found that rainfall increases on average by $2.4 \%$ per $100 \mathrm{~m}$ (coefficient of determination is $0.62, n=7$ ), while temperature decreases by $0.14{ }^{\circ} \mathrm{C}$ per $100 \mathrm{~m}$ (coefficient of determination is 0.85 , $n=5$ ). The laps rate for temperature is lower than commonly quoted values (e.g., Jacobson, 2005), which might be attributed to the small range of elevation differences of the stations (between 1700 to $2500 \mathrm{~m}$ a.m.s.l.) or due to the local micro-meteorological conditions in the Lake Tana region. For modeling purposes, $2334 \mathrm{~m}$ and $2028 \mathrm{~m}$ were considered reference elevations for rainfall at Upper Gilgel Abay and Koga sub-catchments, respectively, while the elevations of mean temperatures were estimated to $2240 \mathrm{~m}$ and $1900 \mathrm{~m}$ for the sub-catchments, respectively.

Monthly reference crop evapotranspiration $\mathrm{ET}_{0}$ (i.e. for hypothetical grass cover of $12 \mathrm{~cm}$ high with no moisture 
constraints, surface resistance of $70 \mathrm{~s} / \mathrm{m}$ and an albedo of 0.23) has been calculated using the Penman-Monteith equation (Allen et al., 1998). We have used areal monthly values of net radiation, relative humidity, temperature and wind speed. As in many parts in Ethiopia, there are no direct measurements of radiation. Thus, we derived net radiation from sunshine hours measurements within the area. The derived $\mathrm{ET}_{0}$ has been compared to actual $\mathrm{ET}_{\mathrm{a}}$ derived from remote sensing (Water Watch, 2006), as well as to the open water evaporation of Lake Tana (Kebede et al., 2006). A realistic comparison could be detected considering different surfaces (water vs. grass) and different moisture conditions (potential vs. actual). Making use of daily temperature data, other climate parameters were available only on monthly basis, the monthly $\mathrm{ET}_{0}$ has been disaggregated to daily values (Lindstroem et al., 1996), as given by Eq. (1):

$\mathrm{ET}_{0}(t)=\left[1+C_{\mathrm{ET}}\left(T(t)-T_{\mathrm{m}}\right)\right] \mathrm{ET}_{0, \mathrm{~m}}$

Where $\operatorname{ET}_{0}(t)$ is the reference crop evapotranspiration at day $t$ in $[\mathrm{mm} / \mathrm{d}], \mathrm{C}_{\mathrm{ET}}$ correlation factor $\left[1 /{ }^{\circ} \mathrm{C}\right], T(t)$ temperature at day $t\left[{ }^{\circ} \mathrm{C}\right], T_{\mathrm{m}}$ is the long term mean temperature for this day of the year $\left[{ }^{\circ} \mathrm{C}\right]$ and $\mathrm{ET}_{0, \mathrm{~m}}$ is the long term mean evaporation of this month of the year $[\mathrm{mm} / \mathrm{d}]$. The long term mean has been computed from 30 year data records. Because of non-availability of fine classification of land cover over the sub-catchments and making use of the $\mathrm{ET}_{\mathrm{a}}$ map developed by Water Watch (2006), a simple correction has been utilized to scale the reference crop evapotranspiration $\mathrm{ET}_{0}$ (grass) to the potential $\mathrm{ET}_{\text {pot }}$ by the vegetation cover in the area (mixed grass and forest systems). Therefore, $\mathrm{ET}_{0}$ has been scaled up by $10 \%$ to obtain $\mathrm{ET}_{\text {pot }}$, i.e., allowing for extra consumption by trees within the mixed grass land use cover (BECOM, 1999). Errors introduced by this assumption are expected to be small.

The monthly time series of areal rainfall and discharges have been tested for the absence of trends, stability of variance and stability of mean. The analysis demonstrated inconsistencies, non-stationarities and non-homogeneities for several monthly data before 1993. For instance, the Pettitt test, t-test and F-test (at significance level of 5\%) applied to the monthly areal rainfall time series identified two change points in June (1981 and 1988), and one change point in March (1981) for the Upper Gilgel Abay and Koga sub-catchments, respectively. The t-tests exhibited changes in most of the months except July, December, January and February in different years between 1981 and 1992. The annual areal rainfall time series showed change points in 1981, 1987 and 1990 for the two investigated sub-catchments. Similar observations could be made for the discharge time series: i.e., change points were identified in the years between 1981 and 1992 in all months except July and October for Upper Gilgel Abay, and June, August and December for Koga, respectively. Therefore, it has been concluded that the change points and inconsistencies during the earlier periods of the time series are likely to be caused by the poor data quality, as

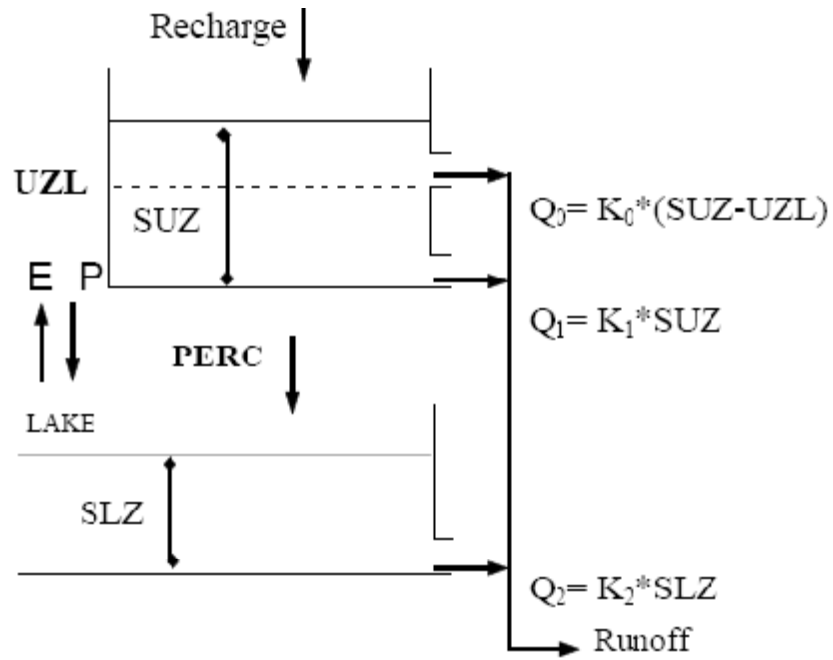

Fig. 3. Schematization of the response routine of the used HBV model; note that the lake part was not applied (source: Seibert, 2002).

all inconsistencies, non-stationarities and non-homogeneities were observed before 1993. Subsequently, data from the hydrologic year 1993/1994 to 2004/2005 were considered suitable for further analysis.

\subsection{The rainfall runoff model}

The widely applied HBV model has been selected to simulate the rainfall runoff processes in the studied catchments as its suitability has been demonstrated under different hydroclimatic conditions world-wide (Bergström, 1995; Lindström et al., 1996). The HBV model is a conceptual hydrological model, which simulates the discharge using input variables of rainfall, temperature and potential evapotranspiration (Bergström, 1976). We have used HBV light (Seibert, 2002), which allows representation of different elevation and vegetation zones. The schematization of the HBV model structure is illustrated in Fig. 3. It consists of different routines representing different processes of snow accumulation and melt (not used for the study area), groundwater recharge and actual evapotranspiration as functions of actual water storage in the soil box (FC). Three runoff components are computed by three linear reservoir equations $Q_{0}, Q_{1}$, and $Q_{2}$ using the three recession coefficients $K_{0}, K_{1}$, and $K_{2}$, respectively. These runoff components typically represent direct runoff $Q_{0}$ (quickly generated, fast runoff component), interflow $Q_{1}$ (intermediate runoff component) and base flow $Q_{2}$ (slow runoff component, normally originating from groundwater). The channel routing is by a triangular weighing function through MAXBAS (length of weighing function). The soil moisture threshold for reduction of evapotranspiration defines LP. The maximal flow from upper to lower groundwater box is defined by PERC; $\beta$ is shape coefficient for the 
non-linear storage behaviour of the soil zone. A detailed description of the HBV model is widely available in the literature, e.g., Bergström (1995), Uhlenbrook et al. (1999) among others. The version of the model used in this study is "HBV light" (Seibert, 2002), which corresponds to the version HBV-6 described by Bergström (1992).

The input data used are daily areal rainfall $P(t)$ and temperature $T(t)$ as well as monthly estimates of potential evapotranspiration. Daily $\operatorname{ET}_{\text {pot }}(t)$ were disaggregated from monthly values as discussed above. For the distributed HBV model runs, the areal rainfall and temperatures time series were interpolated for different elevation zones using elevation-relations discussed above.

Different model structures - lumped and semi-distributed - have been tested to investigate the hydrological processes and impacts on the model simulations and transferability. In the semi-distributed computations we modeled varying vegetation and elevation characteristics, up to three vegetations zones were allowed per elevation zone. Therefore, all input data has been prepared for the following three catchment representations (CRs): (i) lumped model structure (CR-I), (ii) lumped model structure with up to three vegetation zones (CR-II), and (iii) semi-distributed model structure with multiple elevation zones and up to three vegetation zones per each elevation zone (CR-III). The vegetation zones in each sub-catchment have been defined based on an actual vegetation cover map of BECOM (1999), which includes grassland, mixed farm land and marshland. The catchment boundaries and elevation zones were estimated using a $90 \times 90 \mathrm{~m}^{2}$ Digital Elevation Model (DEM). This gives 16 and 12 elevation zones of $100 \mathrm{~m}$ intervals for the Upper Gilgel Abay and the Koga sub-catchments, respectively.

\subsection{Assessment of model performance}

Manual adjustments of the model parameters have been done following Monte Carlo simulations (MCS), in order to obtain a process-based representation of the hydrological characteristics in the two sub-catchments. An automatic calibration of the model was avoided because of clear limitations of data (quality and quantity), which hampers any sensible efforts for automatic calibration or sophisticated uncertainty analysis. Having a plausible parameter set for the further analysis was considered more important than a slightly higher model efficiency for a calibration data set of limited quality (danger of over-fitting uncertain data points). The MCS have been carried out to identify the sensitivity of the catchments' runoff generation characteristics, and to explore ranges of model parameters. This has been done by generating more than $1000000 \mathrm{MCS}$, according to the approach introduced by Beven and Binley (1992) for each of the catchment representation in both the Upper Gilgel Abby and Koga sub-catchments. Sensitivity analyses of model parameters have been done through (i) assessing model results for different model structures (three catchment representations), and
Table 1. Parameters and their ranges applied during the Monte Carlo simulations. Note, that the time dependent units change for simulations with more aggregated time steps (15 and 30 days).

\begin{tabular}{|c|c|c|c|c|}
\hline Parameter & Explanation & Unit & Minimum & Maximum \\
\hline \multicolumn{5}{|c|}{ Soil and evaporation routine: } \\
\hline $\mathrm{FC}$ & $\begin{array}{l}\text { Maximum soil moisture } \\
\text { storage }\end{array}$ & $\mathrm{mm}$ & 200 & 600 \\
\hline LP & $\begin{array}{l}\text { Soil Moisture threshold for } \\
\text { reduction of evaporation }\end{array}$ & - & 0.5 & 0.7 \\
\hline$\beta$ & Shape coefficient & - & 1 & 4 \\
\hline \multicolumn{5}{|c|}{ Groundwater and response routine: } \\
\hline$K_{0}$ & Recession coefficient & $\mathrm{d}^{-1}$ & 0.05 & 0.2 \\
\hline$K_{1}$ & Recession coefficient & $\mathrm{d}^{-1}$ & 0.01 & 0.2 \\
\hline$K_{2}$ & Recession coefficient & $d^{-1}$ & 0.006 & 0.05 \\
\hline UZL & Threshold for $K_{0}$-outflow & $\mathrm{mm}$ & 10.2 & 25.6 \\
\hline PERC & $\begin{array}{l}\text { Maximal flow from upper } \\
\text { to lower GW-box }\end{array}$ & $\mathrm{mm} / \mathrm{d}$ & 1.4 & 2.8 \\
\hline \multicolumn{5}{|c|}{ Routing routine: } \\
\hline MAXBAS & $\begin{array}{l}\text { Routing, length of } \\
\text { weighting function }\end{array}$ & $\mathrm{d}$ & 1.5 & 2.9 \\
\hline
\end{tabular}

(ii) analyzing the results of the MC runs (over a million model runs for each CR). An extensive model parameter uncertainty analysis as carried out e.g., by Seibert (1997) or Uhlenbrook et al. (1999) is beyond the scope of this paper, in particular because of limited availability of (high quality) data at the two sub-catchments. The ranges for model parameters for the MC analysis were kept wide (Table 1), but it was avoided to search for suitable parameter sets with not plausible parameter values. Therefore, the experiences of related studies with the same model were used to define the ranges for each parameter (e.g. Seibert, 1997; Uhlenbrook et al., 1999). All sensitivity analyses were done using the daily models.

The model performance was assed visually and statistically using the objective functions by (i) maximizing the model efficiency according to Nash and Sutcliffe (1970), for both normal and logarithmic values $R_{\text {eff }}$, and $\log R_{\text {eff }}$, and (ii) minimizing the volume error (given as mm/a). Despite the limitations of $R_{\text {eff }}$ e.g., as discussed in Schaefli and Gupta (2007), it was still considered as a suitable measure to assess the simulation results in combination with other objective function and visual inspections. An automatic calibration procedure was not applied here, as besides optimizing the mentioned objective functions, a meaningful parameterization from a process point of view was important, in particular with the additional objective in mind to test model transferability.

Model validations have been done using different time periods, i.e. 2000/2001 to 2004/2005 for Upper Gilgel Abay and 2001/2002 to 2004/2005 for Koga. The model parameters transferability has been tested by interchanging the best model parameter sets for different simulation time steps $(1$, 

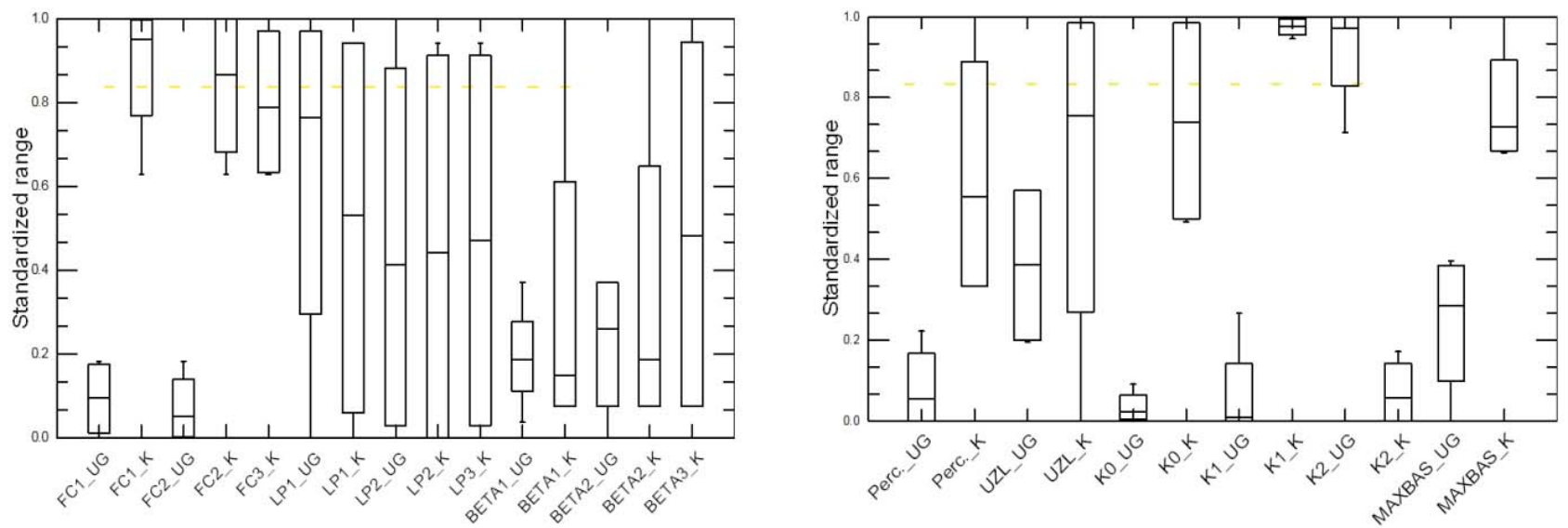

Fig. 4. Standardized sensitive value ranges of soil and evaporation routine (left panel) and groundwater, response and routing function model parameters (right panel); the suffixes UG and K stand for Upper Gilgel Abay and Koga sub-catchments, respectively.

15 and 30 days) between the two sub-catchments Upper Gilgel Abay and Koga. The available data sets of the two (poorly) gauged catchments were considered as too limited to do further model regionalisation investigations. Finally, we distinguished different hydrological responses of the two sub-catchments by comparing the most sensitive parameters.

\section{Results and discussion}

\subsection{Calibration and validation of daily models}

The Monte Caro runs were generated to investigate the catchment response characteristics, and to explore physically realistic model's parameters ranges. Initial Monte Carlo simulations were generated using parameter values from the literature (tuned with preliminary model runs) to define possible parameter ranges as shown in Table 1. The definition of the parameters is given in Sect. 3.2 above. Different parameter sets were produced by running more than 1000000 MCS for each CR of the Upper Gilgel and Koga sub-catchments on daily time steps. The results obtained give highest model efficiency $R_{\text {eff }}$ for the Upper Gilgel Abay (CR-I) and for Koga (CR-III) of 0.80 and 0.63 , respectively. For all CRs, highest $R_{\text {eff }}$ values resulted in volume error $(\Delta Q)$ of $0 \%, 4 \%$ and 5\% for CR-I, CR-II and CR-III, in Upper Gilgel Abay, while these are $2 \%, 6 \%$ and $5 \%$ in Koga, respectively. $\Delta Q$ is the mean annual difference between observed and simulated runoff volumes. Several model parameter sets with $R_{\text {eff }}$ comparable to the highest values were obtained. In the Upper Gilgel Abay 228 087; 158954 and 95043 MCS resulted in $R_{\text {eff }}>0.75$ (good performance) for CR-I, CR-II and CR-III, respectively; in Koga these are 497; 202 and 1922 parameter sets that yielded $R_{\text {eff }}>0.6$ (satisfactory performance). In addition to visual inspection and evaluation of low flows $\left(\log R_{\text {eff }}\right)$, we consider $R_{\text {eff }}>0.6$ as satisfactory,
$R_{\text {eff }}>0.7$ as good and $R_{\text {eff }}>0.80$ as very good performances. The parameters for which the models were highly sensitive, i.e. yielding good simulations only for comparable small intervals, were related to the soil moisture storage and runoff generation routine as depicted by the standardized parameter values of the box plots given in Fig. 4. It shows the smallest and largest parameter values that produced $R_{\mathrm{eff}}>$ 0.75 for the Upper Gilgel Abay and $>0.6$ for Koga. A good model performance $\left(R_{\mathrm{eff}}>0.75\right)$ was achieved in the Upper Gilgel Abay with FC (soil moisture storage) around the lower side of the range $(206<\mathrm{FC}<285 \mathrm{~mm})$, whereas satisfactory $\left(R_{\mathrm{eff}}>0.60\right)$ model efficiencies were obtained in Koga with FC near the maximum of the parameter range $(490<\mathrm{FC}<599 \mathrm{~mm}$ ). The soil routine parameter $\beta$ (shape coefficient) and the runoff routine parameters PERC (maximum flow from upper to lower reservoirs) and UZL (threshold for $K_{0}$ flow) were found to be the most sensitive parameters only in the Upper Gilgel Abay. The recession curve - reflecting storage outflow relation and $K_{2}$ - appeared to be sensitive to high values in the Upper Gilgel Abay and low values in Koga sub-catchment. The FC values show that the soils of the Upper Gilgel Abay retain about half the water (per unit area) as compared to Koga sub-catchment. In other words, a major portion of the rainfall received in Upper Gilgel Abay leaves the catchment quickly as direct runoff, while most of the rainfall falling in the Koga is rather stored and released afterwards by evapotranspiration and base flow. This phenomenon has also been corroborated by a water balance analysis, i.e., higher actual evaporation and lower total discharge were estimated in the Koga (details are not given here). The previous analysis signified different ranges of most sensitive model parameters in the two sub-catchments, which reflects different hydrological processes between the two. This suggests different dominant runoff generation processes in the two sub-catchments. 
Table 2. Calibration parameters and model efficiency results for calibration and validation of the daily models for the three Catchment Representations (CRs) of the sub-catchments Upper Gilgel Abay (1995/1996 to 1999/2000) and Koga (1996/1997 to 2000/2001).

\begin{tabular}{|c|c|c|c|c|c|c|c|c|c|c|c|c|c|c|c|}
\hline \multirow{3}{*}{$\begin{array}{l}\text { Calibration/ } \\
\text { Validation }\end{array}$} & \multirow[t]{3}{*}{ Parameters } & \multicolumn{7}{|c|}{ Upper Gilgel Abay } & \multicolumn{7}{|c|}{ Koga } \\
\hline & & \multirow[t]{2}{*}{ CRI } & \multicolumn{3}{|c|}{ CRII } & \multicolumn{3}{|c|}{ CRIII } & \multirow[t]{2}{*}{ CRI } & \multicolumn{3}{|c|}{ CRII } & \multicolumn{3}{|c|}{ CRIII } \\
\hline & & & Zone 1 & Zone 2 & Zone 3 & Zone 1 & Zone 2 & Zone 3 & & Zone 1 & Zone 2 & Zone 3 & Zone 1 & Zone 2 & Zone 3 \\
\hline \multirow[t]{11}{*}{ Parameters } & $\mathrm{FC}[\mathrm{mm}]$ & 233 & 240 & 195 & - & 230 & 204 & - & 559 & 525 & 491 & 599 & 540 & 480 & 590 \\
\hline & $\mathrm{LP}[-]$ & 0.68 & 0.68 & 0.65 & - & 0.64 & 0.64 & - & 0.61 & 0.5 & 0.5 & 0.5 & 0.5 & 0.5 & 0.5 \\
\hline & $\beta[-]$ & 1.4 & 1.5 & 1.4 & - & 1.4 & 1.1 & - & 2.0 & 2.0 & 1.7 & 1.8 & 2.1 & 1.9 & 2.1 \\
\hline & $K\left[\mathrm{~d}^{-1}\right]$ & 0.06 & & 0.06 & & & 0.06 & & 0.15 & & 0.14 & & & 0.11 & \\
\hline & $K_{1}\left[\mathrm{~d}^{-1}\right]$ & 0.05 & & 0.11 & & & 0.08 & & 0.18 & & 0.18 & & & 0.18 & \\
\hline & $K_{2}\left[\mathrm{~d}^{-1}\right]$ & 0.05 & & 0.04 & & & 0.04 & & 0.01 & & 0.01 & & & 0.01 & \\
\hline & UZL $[\mathrm{mm}]$ & 20.5 & & 20.4 & & & 19.7 & & 18.9 & & 18.7 & & & 19.5 & \\
\hline & $\operatorname{PERC}[\mathrm{mm} / \mathrm{d}]$ & 1.70 & & 2.10 & & & 1.96 & & 2.48 & & 2.20 & & & 2.23 & \\
\hline & MAXBAS [d] & 1.92 & & 1.95 & & & 1.84 & & 2.47 & & 2.46 & & & 2.45 & \\
\hline & $R_{\text {eff }}[-]$ & 0.80 & & 0.78 & & & 0.79 & & 0.62 & & 0.62 & & & 0.61 & \\
\hline & $\log R_{\text {eff }}[-]$ & 0.78 & & 0.82 & & & 0.85 & & 0.71 & & 0.72 & & & 0.68 & \\
\hline \multirow[t]{4}{*}{ Calibration } & $R^{2}[-]$ & 0.80 & & 0.78 & & & 0.79 & & 0.63 & & 0.64 & & & 0.63 & \\
\hline & $\Delta Q[\mathrm{~mm} / \mathrm{a}]$ & 0.00 & & 0.00 & & & 0.00 & & 0.00 & & 0.00 & & & 0.00 & \\
\hline & $R_{\text {eff }}[-]$ & 0.84 & & 0.83 & & & 0.84 & & 0.60 & & 0.61 & & & 0.60 & \\
\hline & $\log R_{\text {eff }}[-]$ & 0.88 & & 0.91 & & & 0.91 & & 0.76 & & 0.77 & & & 0.74 & \\
\hline \multirow[t]{2}{*}{ Validation } & $R^{2}[-]$ & 0.85 & & 0.84 & & & 0.84 & & 0.60 & & 0.62 & & & 0.61 & \\
\hline & $\Delta Q[\mathrm{~mm} / \mathrm{a}]$ & -52 & & -53 & & & -51 & & 12 & & 6 & & & 6 & \\
\hline
\end{tabular}

Next, we modified the parameter values through manual calibration, again with the objective to obtain highest $R_{\text {eff }}$ values and lowest volume errors $(\Delta Q)$ in addition to visual inspection of the hydrographs. We believe that this is justifiable and preferred to automatic calibration to allow for a better process-based description of the runoff generation mechanisms in these two sub-catchments. The process observations from the field visits and knowledge of reasonable parameter values from other HBV applications (e.g., Seibert, 1997; Uhlenbrook et al., 1999) gave strong hints. The calibration results for the three CRs (1995/1996 to 1999/2000 for Upper Gilgel Abay and 1996/1997 to 2000/2001 for Koga) are shown in Fig. 5 and Table 2 together with the corresponding statistical measures for model performance assessment; see Sect. 3.2 for the definition of model parameters $R^{2}$ is the coefficient of determination. The visual inspection of the hydrographs of Fig. 5 indicates generally good flow simulations in particular during the recession flows, while the short-term fluctuations during the high-flow season were not modeled well, in particular for the Koga catchment. For all CRs the agreement between observed and simulated runoff is good in the Upper Gilgel Abay $\left(R_{\text {eff }}>0.78\right)$ and satisfactory in Koga $\left(R_{\mathrm{eff}}>0.6\right)$. The mean annual differences between observed and simulated runoff $(\Delta Q)$ is negligible The agreement between simulated and observed low flows is good in the Upper Gilgel Abay $\left(\log R_{\text {eff }}>0.78\right)$ and acceptable in Koga catchment $\left(\log R_{\text {eff }}>0.68\right)$. The coefficient of determination $R^{2}$ is $>0.8$ for the Upper Gilgel Abay and $>0.7$ for the Koga catchment.

The validation results for the two sub-catchments (2000/ 2001 to 2004/2005 for Upper Gilgel Abay and 2001/2002 to 2004/2005 for Koga) indicated better efficiencies compared to the calibration results (graphical and tabular details are not presented here, only a summary). For all the three CRs in Upper Gilgel Abay the model efficiencies were generally very good $\left(R_{\text {eff }}>0.83\right)$, even though the model overestimated the observed discharge by about $52 \mathrm{~mm} / \mathrm{a}(5 \%)$. Low flow simulations were also very good $\left(\log R_{\text {eff }}>0.84\right)$. The model validation results in the Koga sub-catchment are comparable to the calibration results, yet, during the validation period the model has shown better performance in simulating low flows $\left(\log R_{\text {eff }}>0.73\right)$. The high $\log R_{\text {eff values obtained in }}$ both sub-catchments confirmed better performances in simulating low flows. The reason that model simulations during the validation period are tentatively better compared to the calibration, is likely to be caused by the better data quality (less missing values) for the later years. We do not want to speculate about other physical explanation.

The well simulated recession hydrograph indicates a good model representation of catchment characteristics that govern the water storage and delayed flow components generation. In other words, this depicts the strength of the HBV model's soil routine and runoff generation routine and their ability to reproduce good rainfall-runoff relation during mean and low flow periods. The inability of the model to simulate the daily pattern of flood flows, which is even more noticeable in the Koga catchment, could be caused by three factors. First, the given network of rainfall stations (see Fig. 2) may not capture the areal variability of daily rainfall patterns well enough (i.e. only four stations in Upper Gilgel Abay and three in Koga were available). That interpolation errors may directly influence runoff predictions stronger in the smaller Koga as compared to the larger Upper Gilgel Abay sub-catchment. Second, the daily observed 

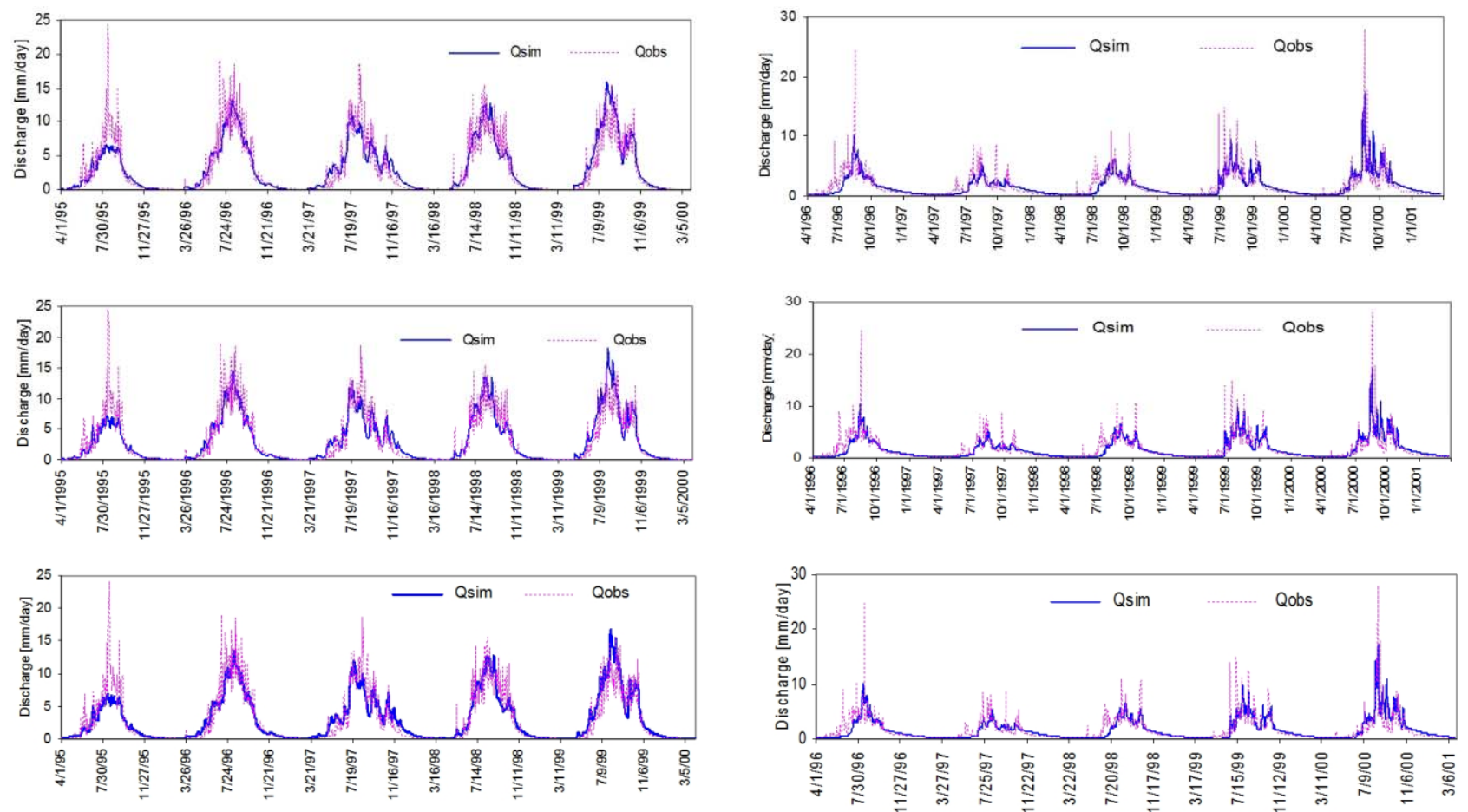

Fig. 5. Simulated and observed stream flows in mm/d for CR-I (upper), CR-II (middle), and CR-III (bottom) for the two sub-catchments in Upper Gilgel Abay (left) and Koga (right), during the calibration period (daily model results).

discharges derived from two water level measurements (at 06:00 a.m. and 06:00 p.m.) may have smoothened a very rapid flow characteristics at the site. The often turbulent nature of the flows at the sites imply a dynamic river bed profile at the measuring section, such that a mean rating curve may not properly capture the dynamic nature of the water leveldischarge relationship. Although the Gilgel Abay catchment is one of the best monitored catchments in the Upper Blue Nile, this analysis clearly recommends additional measurements and better methods (i.e. a better cross-section, higher resolution of observations) to confirm the validity of the observations. In fact this is undertaken now as part of a new research program in the Blue Nile led by UNESCO-IHE, Addis Ababa University and other partners from the region. Third, the runoff generation mechanisms during floods are too complex for the relatively simple HBV conceptual model to simulate. This might be caused by temporary water storage in the catchment (i.e. at areas close to the channel network) and overflows when storage capacity is exceeded. As estimated from the topographic maps and field observations, the areas close to the channel network, which are seasonally subject to over spilling inundation are about $56 \mathrm{~km}^{2}$ and $107 \mathrm{~km}^{2}$ in Upper Gilgel Abay and Koga sub-catchments, respectively. The relatively larger inundated area in the Koga is also confirmed by regional soil moisture map of Water Watch (2006). The HBV model with the given model structure could not deal with such a complexity of hydrological processes. A fully distributed and better process-based model structure (e.g. Uhlenbrook et al., 2004; Wissmeier and Uhlenbrook, 2007) would be needed.

\subsection{Discussion of discharge modeling results}

Here we discuss results of varying model structures (i.e. different catchment representations and varying modeling time steps) and assess implications on the simulated runoff. We also tested the possibility to transfer model parameters, as well as the separation of runoff hydrograph as two additional outputs of the modeling exercise.

\subsubsection{Effect of different catchment representations}

Satisfactory model efficiencies could be obtained for the simulation (calibration and validation periods) of all the three catchment representations in the two sub-catchments, see Table 2, and Fig. 6. It is remarkable that the goodness of the simulations is only slightly influenced by the different model structures. The semi-distributed model version (CR-III) gives slightly better performance in the Upper Gilgel Abay, while in Koga the model efficiency is highest for the lumped representation with multiple vegetation zones (CR-II). The results of CR-II in Upper Gilgel Abay are comparable to the semi-distributed catchment representation 

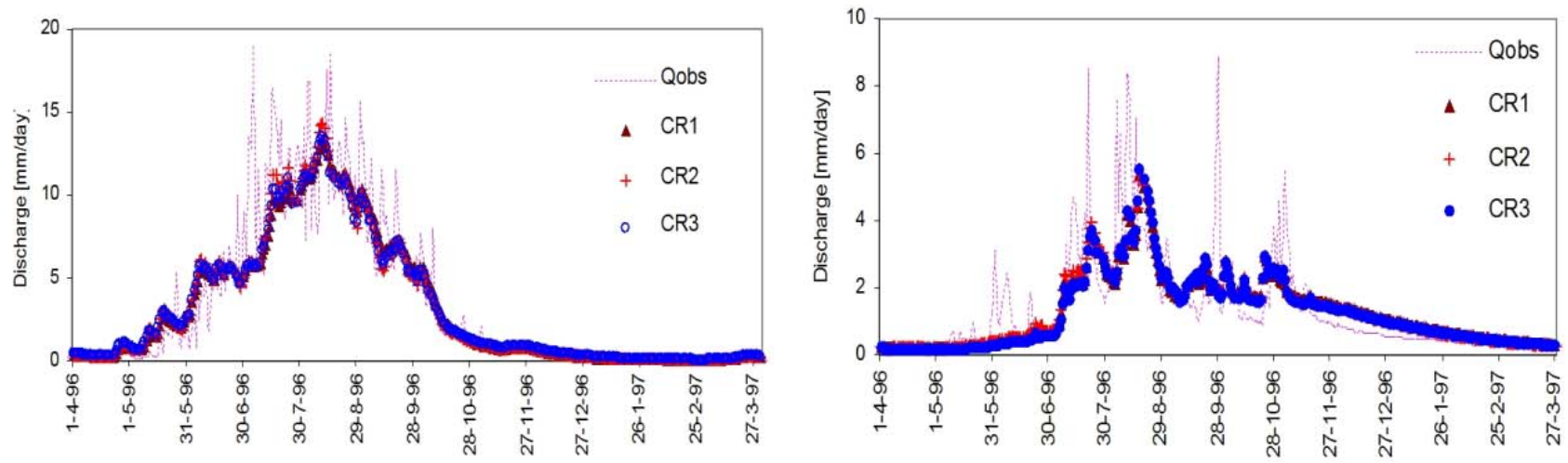

Fig. 6. Flow simulations of the three different catchment representations CR-I, CR-II, and CR-III for the Upper Gilgel Abay (left) and Koga (right) sub-catchments in the hydrological year 1996/1997 (daily model results).
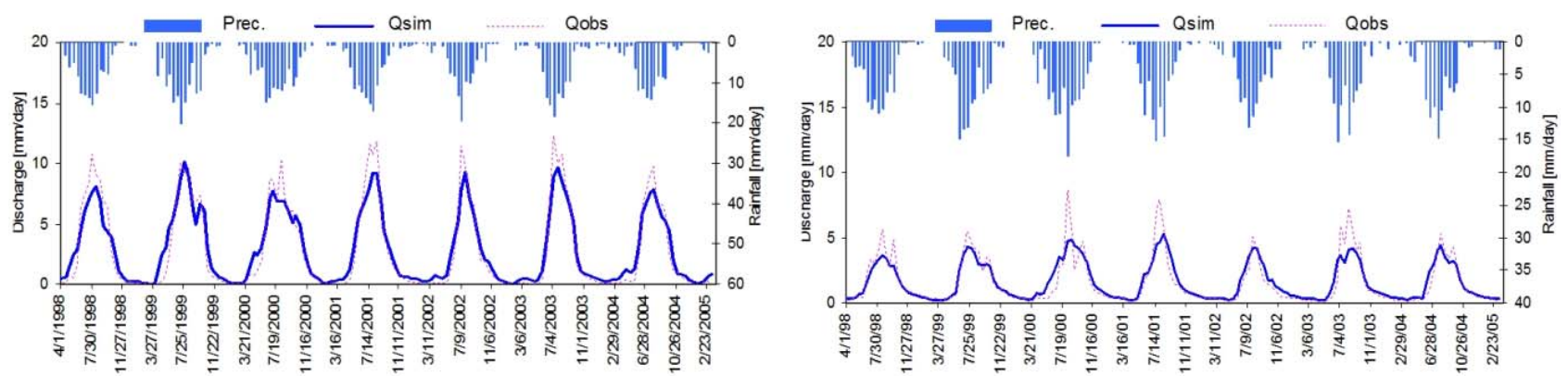

Fig. 7. Observed precipitation, and observed and simulated stream flows for 15 days time step (CR-III) during 1998/1999 to 2004/2005 for the sub-catchments Upper Gilgel Abay (left) and Koga (right).

(CR-III). Accordingly, it can be concluded that model structure has a minor effect on the accuracy of the predicted runoff. However, the distributed water balance predictions in the semi-distributed case (CR-III) produces more spatial variability of the water balance fluxes, which makes sense from a process based point of view agreeing with the concept that different elevation and vegetation zones are characterized by different water fluxes. But increasing the model complexity and larger variability of hydrological variables did not result in better predictions at the sub-catchment scale. In other words, with increasing degree of freedom through more model parameters (CR-III > CR-II > CR-I) does not result in an improvement of performance. Hence, it can be concluded that the information content available in the input and output data is already explored in the simplest model structure (CR-I).

\subsubsection{Effect of varying time steps}

When increasing the computational time step from daily to 15 and 30 days time steps (using aggregated 15 and 30 days data sets, respectively), the new calibration results gave better model performance for the two sub-catchments compared to daily simulations (Fig. 7) This is expected, as large daily fluctuations during the wet season are smoothened out. The simulated average peak discharge is often higher than observed, except in the years 1999/2000 (Upper Gilgel Abay) and 2002/2003 and 2004/2005 (Koga). The model efficiencies $R_{\text {eff }}$ of the 15-days models are $>0.80$ and the water balance error $\Delta Q$ is low (1 to $2 \%$ in the two sub-catchments). However, increasing the time step showed contrasting performances in simulating low flows compared to daily simulations in both catchments. The $\log R_{\text {eff }}$ declined in the Upper Gilgel Abay for the calibration period from 0.85 to 0.82 and for the validation period from 0.91 to 0.74 , respectively. While low flow predictions improved in the Koga catchment, with $\log R_{\text {eff }}$ for larger time steps increased in the Koga subcatchment from 0.68 to 0.85 during the calibration period and from 0.74 to 0.88 during the validation period.

\subsubsection{Partitioning of the flow hydrograph}

The mean annual direct runoff $\left(Q_{\mathrm{DR}}\right)$, interflow $\left(Q_{\mathrm{IF}}\right)$ and base flow $\left(Q_{\mathrm{BF}}\right)$ components of the total hydrograph computed by the HBV model are given in Table 3 . The distribution of components in the Koga sub-catchment is similar for all tested model structures, but varies somewhat more in the Upper Gilgel Abay sub-catchment. In general $Q_{\mathrm{IF}}$ is large 
Table 3. Statistics of direct runoff $Q_{\mathrm{DR}}$, interflow $Q_{\mathrm{IR}}$ and base flow $Q_{\mathrm{BF}}$ components (c.f. $Q_{0}, Q_{1}$ and $Q_{2}$ in Fig. 3) of the models for the period 1996/1997-2004/2005.

\begin{tabular}{|c|c|c|c|c|c|c|c|c|c|c|}
\hline \multirow{2}{*}{\multicolumn{2}{|c|}{$\begin{array}{c}\text { Catchment representation } \\
\text { Runoff component }\end{array}$}} & \multicolumn{3}{|c|}{ CR-I } & \multicolumn{3}{|c|}{ CR-II } & \multicolumn{3}{|c|}{ CR-III } \\
\hline & & \multirow{2}{*}{$\begin{array}{r}Q_{\mathrm{DR}} \\
321\end{array}$} & \multirow{2}{*}{$\frac{Q_{\mathrm{IF}}}{453}$} & \multirow{2}{*}{$\begin{array}{r}Q_{\mathrm{BF}} \\
314\end{array}$} & \multirow{2}{*}{$\begin{array}{r}Q_{\mathrm{DR}} \\
155\end{array}$} & \multirow{2}{*}{$\begin{array}{l}Q_{\mathrm{IF}} \\
587\end{array}$} & \multirow{2}{*}{$\begin{array}{r}Q_{\mathrm{BF}} \\
347\end{array}$} & \multirow{2}{*}{$\begin{array}{r}Q_{\mathrm{DR}} \\
221\end{array}$} & \multirow{2}{*}{$\begin{array}{r}Q_{\mathrm{IF}} \\
513\end{array}$} & \multirow{2}{*}{$\begin{array}{r}Q_{\mathrm{BF}} \\
352\end{array}$} \\
\hline Upper & Mean $Q(\mathrm{~mm} / \mathrm{a})$ & & & & & & & & & \\
\hline Gilgel & $\%$ to total & $29 \%$ & $42 \%$ & $29 \%$ & $14 \%$ & $54 \%$ & $32 \%$ & $20 \%$ & $47 \%$ & $32 \%$ \\
\hline \multicolumn{11}{|l|}{ Abay } \\
\hline \multirow{2}{*}{ Koga } & Mean $Q(\mathrm{~mm} / \mathrm{a})$ & 18 & 207 & 291 & 15 & 234 & 270 & 17 & 237 & 264 \\
\hline & $\%$ to total & $4 \%$ & $40 \%$ & $56 \%$ & $3 \%$ & $45 \%$ & $52 \%$ & $3 \%$ & $46 \%$ & $51 \%$ \\
\hline
\end{tabular}

in both sub-catchments (40 to $54 \%$ ), while $Q_{\mathrm{BF}}$ is noticeably dominant in the Koga (>50\%) with a very small $Q_{\mathrm{DR}}$ ( $4 \%$ ). The direct runoff in Upper Gilgel Abay (14 to 29\%) has almost the same order of magnitude as the base flow $(\sim 30 \%)$. The large difference of direct runoff components between the two sub-catchments, demonstrates a distinct difference in the fast response characteristics between the two. This is also supported by the topography and the existence of dambos as mentioned above. The derived groundwater contributions (assuming the base flow component, $Q_{\mathrm{BF}}$, represents the groundwater flow component) of the Upper Gilgel Abay and Koga sub-catchments are higher in the latter, though generally slightly higher, but comparable to the results of BCEOM (1999) who estimated groundwater contributions of $305 \mathrm{~mm} / \mathrm{a}$ and $203 \mathrm{~mm} / \mathrm{a}$, respectively.

\subsubsection{Transferability of model parameters}

As typical to other catchments in the Blue Nile river basin, about half of the whole Gilgel Abay catchment is ungauged (Fig. 2). Therefore, despite data limitation, a method for model transferability would be very useful to provide key information for water management purposes. We have carried out transferability tests of the obtained models and parameter sets to assess the possibility of regionalization to other sub-catchments. This has been done by applying the best set of calibration parameters obtained for one sub-catchment to the other and vice versa. The selected parameter sets from the Upper Gilgel Abay did not perform well in the Koga for daily time step, whereas those of Koga yielded satisfactory performance in the Upper Gilgel Abay, see Table 4. In general, transferability results showed poorer performance of the daily model in both sub-catchments, e.g., $R_{\text {eff }}$ reduces from about 0.8 to 0.67 in the Upper Gilgel Abay and from 0.6 to 0.3 in the Koga sub-catchment. Poorer base flow simulations were also confirmed by the $\log$-efficiencies $\log R_{\text {eff }}$. The high $\Delta Q$ values (19\% in Upper Gilgel and $40 \%$ in Koga) corroborates that achieving good daily modeling results by transferring parameter sets directly between sub-catchments in the region is not likely to yield good results.
The transferability of model results for the 15 and 30 days time step models showed significantly better results compared to daily models (cf. Hartmann and Bárdossy, 2005). The tests showed good performance in both catchments with $R_{\text {eff }}$ of about 0.80 in the two sub-catchments and low $\Delta Q$ values. However, from visual inspections of the hydrographs it was clear that the simulated discharge overestimated the recession flow of the Upper Gilgel Abay and underestimated that of Koga River, which is in line with the results of the flow component analysis given in the previous section. Attenuation of peak runoff was also noted in the hydrographs of both sub-catchments. Therefore, it has been concluded that transferability of model parameters from hydrologic process point of view (best represented by daily models) is not feasible. However, the tests demonstrated transferability of model parameters on longer time scales (15 and 30 days), which is a useful result for operational management of water resources in this data scarce region.

In general, from the similarity of the inaccuracies induced by transferring the model parameters between the two subcatchments (which were mainly in the rising limb and recession curves of the hydrograph) together with the outcome of the parameter sensitivity analysis using MCS, it has been concluded that the difference in hydrologic behavior in the two sub-catchments hampered the parameters transfer between the two. To obtain better results in regionalization of a hydrologic model as acquired elsewhere (e.g., Seibert, 1999; Hundecha and Bárdossy, 2004; Masih et al., 2010) would need for instance establishing functional relationships between catchment characteristics (land use, soil type, size, slope and shape) and model parameters and a better characterization of the similarity of the catchments. However, distribution and the limited number of meteorological and flow gauging stations did not allow following such an approach in the Gilgel Abay catchments. 
Table 4. Model performance for transferability tests for 1, 15 and 30 day time steps, of CR-III for Upper Gilgel Abay and Koga subcatchments. Calibration and validation results included for comparison.

\begin{tabular}{llrrrrl}
\hline $\begin{array}{l}\text { Model } \\
\text { time step }\end{array}$ & Sub-catchment & $R_{\text {eff }}$ & $\begin{array}{r}\log R_{\text {eff }} \\
{[-]}\end{array}$ & $\begin{array}{c}R^{2} \\
{[-]}\end{array}$ & $\begin{array}{r}\Delta Q \\
{[\mathrm{~mm} / \mathrm{a}]}\end{array}$ & Remark \\
\hline Daily & Upper Gilgel Abay & 0.79 & 0.85 & 0.79 & 0 & Calibration \\
& & 0.84 & 0.91 & 0.84 & -51 & Validation \\
& & 0.67 & 0.65 & 0.71 & 210 & Transferred parameters \\
\cline { 2 - 7 } & Koga & 0.61 & 0.68 & 0.63 & 0 & Calibration \\
& & 0.60 & 0.74 & 0.61 & 6 & Validation \\
& & 0.33 & -0.34 & 0.65 & -211 & Transferred parameters \\
\hline \multirow{2}{*}{ 15 days } & \multirow{2}{*}{ Upper Gilgel Abay } & 0.84 & 0.82 & 0.87 & 0 & Calibration \\
& & 0.93 & 0.74 & 0.96 & -7 & Validation \\
& & 0.86 & 0.58 & 0.93 & -12 & Transferred parameters \\
\cline { 2 - 7 } & \multirow{2}{*}{ Koga } & 0.81 & 0.85 & 0.83 & 0 & Calibration \\
& & 0.81 & 0.88 & 0.84 & -12 & Validation \\
& & 0.80 & 0.37 & 0.80 & -12 & Transferred parameters \\
\hline 30 day & \multirow{2}{*}{ Upper Gilgel Abay } & 0.84 & 0.73 & 0.88 & 0 & Calibration \\
& & 0.88 & 0.74 & 0.92 & -1 & Validation \\
& & 0.84 & 0.70 & 0.91 & 57 & Transferred parameters \\
\cline { 2 - 6 } & Koga & 0.85 & 0.82 & 0.85 & 0 & Calibration \\
& & 0.86 & 0.85 & 0.87 & -7 & Validation \\
& & 0.78 & 0.23 & 0.85 & -120 & Transferred parameters \\
\hline
\end{tabular}

\section{Conclusions}

The water balance dynamics and dominant hydrological processes in the Gilgel Abay catchment (source region of the Blue Nile) were investigated using a conceptual hydrological model. The overall model results for different simulation time steps (1, 15 and 30 days) are reasonable and were even better during the model validation period which gives a hint to the better data quality. Longer simulation time steps gave clearly better simulation results, which can be explained by the data quality and model insufficiencies that become less important for longer time steps due to averaging out effects. Testing different model structures (lumped to semidistributed) did not result in significantly different model performances, indicating that the information content of the data can already be explored with a simple lumped model.

The computed direct runoff, interflow and base flow components by the HBV models in the two sub-catchments for different model structures seem reasonable and are comparable to literature values derived by other methods. The runoff generation in the Upper Gilgel Abay sub-catchment is mainly dominated by quick flow of about $70 \%$ (direct runoff and interflow components), while in Koga sub-catchment this component is less important (40 to 50\%). The direct runoff in the Koga is noticeably smaller (4\%) compared to the Upper Gilgel Abay (14 to 30\%). The water storage and base flow production in the Koga sub-catchment is larger, very likely due to the existence of marshland and dambos, which could not be adequately simulated with the present version of the HBV model. The field observations, topographic features and satellite-derived maps of soil moisture support the relatively larger storage in the Koga compared to the Upper Gilgel Abay. The dissimilarities between the two subcatchments have hampered the transferability of model parameters between the two, and hence ultimately the regionalization of the model. However, satisfactory results could be obtained when transferring model parameters of longer simulation time steps (15 and 30 days), which is very useful for water resources planning in that region.

The results of the study clearly demonstrate successes and failures of hydrological modeling in a data limited environment in Africa. It is recommended to obtain better areal rainfall predictions for the study area (e.g., use of remote sensing and additional rain gauges), and equally important a regularly updated rating curves at the discharge gauges. The hydrological functioning of marshlands and dambos in particular in the Koga sub-catchment is not fully understood based on this analysis, however, the impacts of these features on runoff response pattern could be shown. To gain further insights into the hydrological processes detailed process studies combining experimental (tracer studies, geophysics etc.) and modeling methods are needed. 
Acknowledgements. The hydrological data used in the project were obtained from the Ministry of Water Resources (MoWR), Ethiopia. The meteorological data were obtained from National Meteorological Agency of Ethiopia. The Ministry of Water Resources of Ethiopia provided GIS data sets of land use, land cover and data of the geology of the study area.

The study was partly supported by the IAEA, Water Resources Section, Vienna, Austria, and through the Dutch fellowship program (Nuffic) through a research fellowship for Ashenafi Gragne. Thanks to W. G. M. Bastiaanssen (Water Watch, Wageningen, and Delft University of Technology, The Netherlands) for providing an image of the extent of oversaturated soils for the study area, which helped to identify the dambos in the Koga catchment. Thanks are also due to Seifu Kebede (Addis Ababa University) for supporting the study in its early stages.

Edited by: M. Sivapalan

\section{References}

Allen, R. G., Pereira, L. S., Raes, D., and Smith, M.: Crop evapotranspiration: guidelines for computing crop water requirements, United Nations FAO, Irrigation and Drainage Paper 56, Rome, Italy, 300 pp., 1998.

BCEOM: Abay River Basin integrated master plan, main report, MoWR, Addis Ababa, Ethiopia, 1999.

Bastiaanssen, W. G. M., Menenti, M., Feddes, R. A., and Holtslag, A. A. M.: The Surface Energy Balance Algorithm for Land (SEBAL): Part 1 formulation, J. Hydrol., 212-213, 198-212, 1998.

Bergström, S.: Development and application of a conceptual runoff model for Scandinavian catchments, Bull. Series A52, University of Lund, 134 pp., 1976.

Bergström, S.: The HBV-model - its structure and applications, SMHI Reports RH No. 4, Norrköping, Sweden, 1992.

Bergström, S.: The HBV model, in: Computer models of watershed hydrology, edited by: Singh, V. P., Water Resources Publications, Highlands Ranch, Colorado, USA, 443-476, 1995.

Beven, K. J. and Binley, A.: The future of distributed models: model calibration and uncertainty prediction, Hydrol. Process., 6, 279-298, 1992.

Chang, M.: Forest Hydrology: An Introduction to Water and Forests, CRC Press, Boca Raton, London, New York, Washington, DC, 2003.

Conway, D. and Hulme, M.: Recent Fluctuations in Precipitation and Runoff over the Nile sub-basins and their impact on main Nile drainage, Climatic Change, 25, 127-151, 1993.

Dahmen, E. R. and Hall, M. J.: Screening of Hydrological Data, ILRI, 49, The Netherlands, 1990.

El-Khodari, N.: The Nile River: challenges to sustainable development, Presentation to the River symposium, 2003.

Hartmann, G. and Bárdossy, A.: Investigation of the transferability of hydrological models and a method to improve model calibration, Adv. Geosci., 5, 83-87, 2005, http://www.adv-geosci.net/5/83/2005/.

Hundecha, Y. and Bárdossy, A.: Modeling of the effect of land use changes on the runoff generation of a river basin through parameter regionalization of a watershed model, J. Hydrol., 292, 281-295, 2004.
Jacobson, M. Z.: Fundamentals of Atmospheric Modeling, 2nd edition, Cambridge University Press, ISBN 0-521-83970-X, 2005.

JICA: Feasibility Report on Power Development at Lake Tana Region, MoWR, Addis Ababa, Ethiopia, 1997.

Johnson, P. A. and Curtis, P. D.: Water Balance of Blue Nile River Basin in Ethiopia, J. Irrig. Drain. E.-ASCE, 120(3), 573-590, 1994.

Kebede, S., Travi, Y., Alemayehu, T., and Marc, V.: Groundwater recharge, circulation and geochemical evolution in the source region of the Blue Nile River, Ethiopia, Appl. Geochem., 20, 1658-1676, 2005.

Kebede, S., Travi, Y., Alemayehu, T., and Ayenew, T.: Water balance of Lake Tana and its sensitivity to fluctuations in rainfall, Blue Nile Basin, Ethiopia, J. Hydrol., 316, 233-247, 2006.

Lahmeyer: Study on Gilgel Abay Scheme, MoWR, Addis Ababa, Ethiopia, 1962.

Lidén, R. and Harlin, J.: Analysis of conceptual rainfall-runoff modelling performance in different climates, J. Hydrol., 238, 231-247, 2000.

Lindström, G., Johansson, B., Persson, M., Gardelin, M., and Bergström, S.: Development and test of the distributed HBV-96 hydrological model, J. Hydrol., 201, 272-288, 1996.

Masih, I., Uhlenbrook, S., Maskey, S., and Ahmad, M. D.: Regionalization of a conceptual rainfall-runoff model based on similarity of the flow duration curve: A case study from the semi-arid Karkheh basin, Iran, J. Hydrol., 391, 188-201, 2010.

Mishra, A., Hata, T., Abdelhadi, A. W., Tada, A., and Tanakamaru, H.: Recession flow analysis of the Blue Nile River, Hydrol. Process., 17, 2828-2835, 2003.

MoWR: Tana - Beles water systems, an overview of water resources, development potentials and issues, Addis Ababa, Ethiopia, 2005.

Mohamed, Y. A., van den Hurk, B. J. J. M., Savenije, H. H. G., and Bastiaanssen, W. G. M.: Hydroclimatology of the Nile: results from a regional climate model, Hydrol. Earth Syst. Sci., 9, 263 278, doi:10.5194/hess-9-263-2005, 2005.

Nash, J. E. and Sutcliffe, J. V.: River flow forecasting through conceptual models, Part I - A discussion of principles, J. Hydrol., 10, 282-290, 1970.

Schaefli, B. and Gupta, H. V.: Do Nash values have value?, Hydrol. Process., 21, 2075-2080, 2007.

Scott, C. A., Bastiaanssen, W. G. M., and ud-Din Ahmad, M. D.: Mapping root zone soil moisture using remotely sensed optical imagery, J. Irrig. Drain. E.-ASCE, 129(5), 326-335, 2003.

Seibert, J.: Estimation of parameter uncertainty in the HBV model, Nord. Hydrol., 28(4/5), 247-262, 1997.

Seibert, J.: Regionalisation of parameters for a conceptual rainfallrunoff model, Agr. Forest Meteorol., 98-99, 279-293, 1999.

Seibert, J.: HBV light users manual, Uppsala University, 2002.

Sivapalan, M., Takeuchi, K., Franks, S. W., Gupta, V. K., Karambiri, H., Lakshmi, V., Liang, X., McDonnell, J. J., Mendiondo, E. M., O'Connell, P. E., Oki, T., Pomeroy, J. W., Schertzer, D., Uhlenbrook, S., and Zehe, E.: IAHS Decade on Predictions in Ungauged Basins (PUB), 2003-2012: Shaping an Exciting Future for the Hydrological Sciences, Hydrolog. Sci. J., 48, 857-880, 2003.

Steenhuis, T. S., Collick, A. S., Awulachew, S. B., Enyew Adgo, A., Abdassalam, A., and Easton, Z. M.: Predicting Discharge and Erosion for the Abay Blue Nile with a Simple Model, 
Proceedings of the Workshop on the Hydrology and Ecology of the Nile River Basin under Extreme Conditions, 1619 June 2008, Addis Ababa, Ethiopia, 2008.

Sutcliffe, J. V. and Parks, Y. P.: The Hydrology of the Nile, IAHS Special Publication no. 5, IAHS Press, Institute of Hydrology, Wallingford, Oxfordshire, UK, 1999.

Tarekegn, D. and Tadege, A.: Assessing the impact of climate change on the water resources of the Lake Tana sub-basin using the WATBAL model, CEEPA, Republic of South Africa, 2005.

Tessema, S. M.: Assessment of temporal hydrological variations due to land use changes using remote sensing/GIS: a case study of Lake Tana Basin, Master Thesis, KTH, Sweden, 2006.

Uhlenbrook, S., Seibert, J., Leibundgut, C., and Rodhe, A.: Prediction of conceptual rainfall-runoff models caused by problems in identifying model parameters and structures, Hydrolog. Sci., 44(5), 779-797, 1999.

Uhlenbrook, S., Roser, S., and Tilch, N.: Hydrological process representation at the meso-scale: The potential of a distributed, conceptual catchment model, J. Hydrol., 291, 278-296, 2004.
Uhlenbrook, S.: Climate and man-made changes and their impacts on catchments, in: KWater Policy 2009, Water as a Vulnerable and Exhaustible Resource, edited by: Kovar, P., Maca, P., and Redinova, J., Proceedings of the Joint Conference of APLU and ICA, 23-26 June 2009, Prague, Czech Republic, 81-87, 2009.

USBR: Land and water resources of the Blue Nile basin, MoWR, Addis Ababa, Ethiopia, 1964.

von der Heyden, C. J. and New, M. G.: The role of dambo in the hydrology of a catchment and the river network downstream, Hydrol. Earth Syst. Sci., 7(3), 339-357, 2005.

Water Watch: Remote sensing studies of Tana-Beles sub-basins, MoWR, Addis Ababa, Ethiopia, 2006.

Wissmeier, L. and Uhlenbrook, S.: Distributed, high-resolution modelling of ${ }^{18} \mathrm{O}$ signals in a meso-scale catchment, J. Hydrol., 332, 497-510, doi:10.1016/j.jhydrol.2006.08.003, 2007. 